\title{
Vision 2030 of Cloud Enterprise Resource Planning Systems (CERPS) in the Kingdom of Saudi Arabia
}

\author{
Nooradeen Adel AlGhazzawi \\ Business Information Technology \& Logistics \\ RMIT University, 80, 445 Swanston St. \\ Melbourne, VIC, 3000, Australia \\ Nouf Essam Katooa \\ Business Information Technology \& Logistics \\ RMIT University, 80, 445 Swanston St. \\ Melbourne, VIC, 3000, Australia
}

Received: April 9, 2019

Accepted: May 20, 2019

Published: May 22, 2019

doi:10.5296/ijmis.v4i1.14644

URL: http://dx.doi.org/10.5296/ijmis.v4i1.14644

\begin{abstract}
Saudi businesses rely on effective data management to trade along their internal and external supply (value) chains and must continually monitor and upgrade legacy data systems. To understand these processes, this study explores the experiences of six diverse Saudi firms as case studies: an air transport data system, vertical integration of global firms' subsidiaries, a value chain system, and entrepreneurs taking advantage of cloud opportunities. Rather than following the literature in focusing on the decision making steps to upgrade organizational data-based resources, this research considers how the firms integrated cloud technologies with their existing or new business models. The case studies were conducted post-implementation of cloud data projects to qualitatively assess the expectations of owners and executives of firms from their initiatives.

Overall, the findings were that firms' experiences when online resulted in better integration with upstream international suppliers, greater cost control, and adapted and new business model advantages. Of the cases, two retailers and an intermediary/retail stationer used their new cloud-based data resources by expanding to online sales platforms. The largest firm was able to use its industry leadership to develop online data integration with firms through its value chains. The remaining firms were more circumspect. The data infrastructure firm
\end{abstract}




\section{Macrothink}

International Journal of Management Innovation Systems

ISSN 1943-1384

2019, Vol. 4, No. 1

merely formed a cloud sibling company to enhance its core business. The airline's industry data provider moved all its clients to cloud services, and the wholesaler similarly agreed to contract with its value chain's digital provider.

This paper is presented as an introduction including the purpose of the study, a short literature review, methodology, results, comparative analysis, and conclusions. There was insufficient opportunity to provide a detailed discussion placing the cases into previous findings, although this empirical study is focussed on cloud migration outcomes rather than change factors.

Keywords: Cloud computing, Enterprise Resource Planning Systems, Cloud ERP systems, Vision 2030, The Kingdom of Saudi Arabia, Information systems adoption 


\section{Mll Macrothink}

International Journal of Management Innovation Systems

ISSN 1943-1384

2019, Vol. 4, No. 1

\section{Introduction}

The introduction comprises background for the study and an explanation of cloud data systems in Saudi Arabia. This is followed by the study's objectives, purpose and significance.

\subsection{Background}

As an emerging economy largely comprised of small traditional suppliers and international corporate subsidiaries, Saudi Arabia had minimal exposure to computerised data systems until mobile technologies became available early this century (Communications and Information Technology Commission, 2017). Al Maliki (2013) explained that the Saudi government saw the economic opportunities from information and communication technologies as creating new professions and job classifications, modernising the Kingdom, and particularly as an impetus for the non-oil private sector's development. However, a decade later, Al Maliki found that several barriers were impeding the vision: the state of the country's technology infrastructure; an education system and educators uninterested in technology; thus lack of technology skills, and also lack of industry pressure to adopt computerised data within the Kingdom's value chains. To this list, Alabdulkarim (2017) added regulatory and proprietary rights issues, thus increased data risk in cloud-based data storage and for all firms.

At the time of this study, the technology industry in Saudi Arabia was highly fragmented. There was high population penetration of mobile voice and data services; however, device use was predominantly for communication, social media, and gaming (Communications and Information Technology Commission, 2017; Sheikh, Islam, Rana, Hameed, \& Saeed, 2017). As noted above, some businesses were slow in moving to computerised data, and lacked trust in the security and reliability of offsite data services (Al-Maliki, 2013). This situation remained, as Akhter (2017) also called for greater management awareness of technology-led business models in the development of the non-oil Saudi private sector. This study responds to this ongoing need.

\subsection{Cloud Technologies in Saudi Arabia}

Cloud technologies were regulated by the Saudi Communication and Information Technology Commission in 2018 (Walden, 2018). Saudi Telecom established a cloud data centre in Riyadh, delivering private and public clouds for data analytics and storage for the private sector in line with Vision 2030, which seeks to diversify the economy and provide new new opportunities in the private sector (Sutton, 2018). Other data service providers include SAP, Microsoft, IBM and others, customising to industry or firm, and Geronimo (2018) reported that in Saudi Arabia such expenditure reached \$US33 billion. Cloud systems are now an accepted part of organisations' business models. Bloomberg Business Week (2018) reported that by 2020, 95 per cent of all Middle East's data traffic would be cloud-based, and take-up across the region is higher than global averages, although starting from a lower base.

Examining the strategies used by Saudi Aramco, the oil and gas corporation, in developing data capacity, the news source Menabytes (2018) reported that the corporation was partnering with a large American firm with its data infrastructure. Further, Vision 2030 initiatives by the 
government were seeking two other large American companies to establish a presence in the Kingdom (Paul, 2017). Nevertheless, issues remain. In studying cloud-hosted business systems in Saudi organisations, Al-Jabri and Alabdulhadi (2016) identified several: senior management commitment, clear objectives for performance of such systems and selection of provider, and operational issues of user training and system maintenance.

\subsection{Study Objectives, Purpose, and Significance}

The purpose of this study was to circumvent the perceived cloud computing barriers of extant literature (e.g., AlBar \& Hoque, 2015) by interviewing management from firms who had upgraded to cloud data services, infrastructure, platforms, software and/or hybrids. The objective of the study was to find strategy trends from managements' use of online data resources that could lead to better prediction of outcomes from future integration of $5^{\text {th }}$ generation technological change: machine learning, artificial intelligence, and integrated devices such as self-driving cars and healthcare support systems (Umar, Sheikh, Deriche, Shoaib, \& Hadi, 2017). Given the diversity in the selected cases, the trend outcomes from this study are of value for both public and private industry policies. The contribution to knowledge for this research was in finding a gap in the literature, which was in identifying post-implementation business models or strategies across a number of industry and business models that could inform future technological disruption in Saudi Arabia.

\section{Literature Review}

This section briefly reviews business technology relevant to Saudi Arabia

\subsection{Business Systems}

Business systems are functional use of data input, storage, processes and retrieval for finance, inventory, sales, supplier and customer relations, and human resources (Manning, Larsen, \& Kannothra, 2018). Data management systems were originally developed for the manufacturing sector for estimating production resources along supply chains (inputs of funds, capacities, labour, and feedstock). The evolution of business information systems from the original mainframes and monitors accelerated in the late 20th century with the personal computer and the internet (Grabski, Leech, \& Schmidt, 2011). Internet capabilities for industry emerged in the early 2000s when landline and cable broadband speeds allowed larger downloads for end-users. Further development of these systems led to multi-location data centres that facilitated secure cloud hosting. This occurred as a rapid shift in internet transit through radio, wire, optical, and electromagnetic systems, forming a framework of thousands of content hosting providers, regional providers and consumer networks (Labovitz, Iekel-Johnson, McPherson, Oberheide, \& Jahanian, 2011).

\subsection{Cloud Technologies}

The United States' Institute of Standards and Technology defined cloud computing as a data management concept enabling convenient, on-demand access to shared computing resources (Mell \& Grance, 2011). Early cloud computing had five characteristics: on-demand self-service, broad network access, resource pooling, rapid elasticity, and these services were 


\section{Macrothink}

International Journal of Management Innovation Systems

ISSN 1943-1384

2019, Vol. 4, No. 1

measured and priced accordingly. Cloud services were aggregated as private (organisation-based), public (open) and a complex hybrid system which now dominates data services (Chunlin \& LaYuan, 2017). Data management was originally available as software as a service (SaaS), platform as a service (PaaS), and infrastructure as a service (IaaS) as described by Cisco (2018) at the figure below.

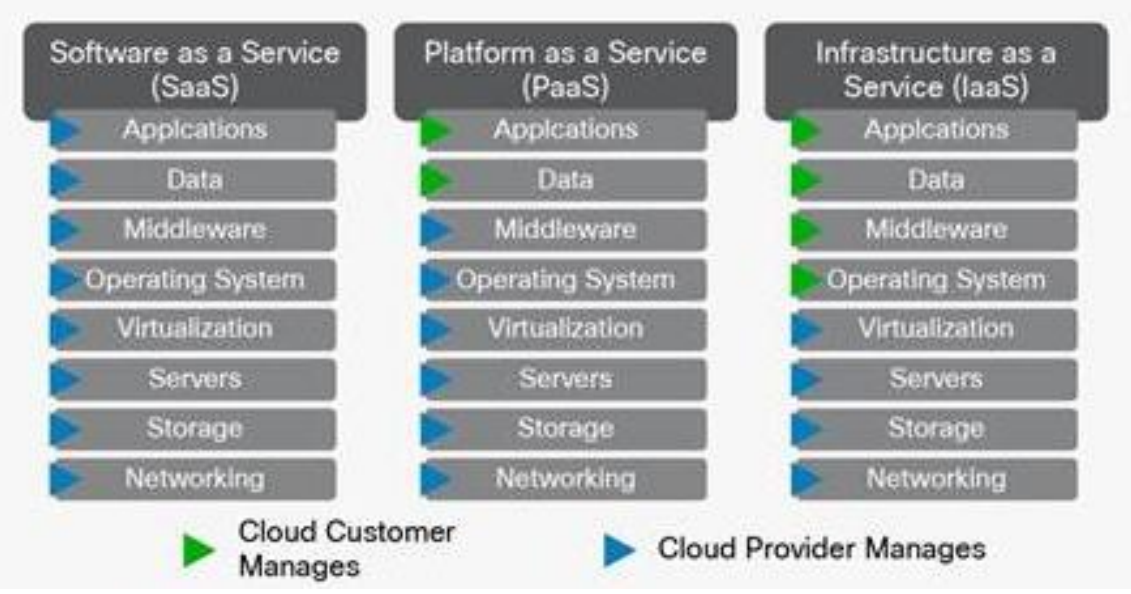

Figure 1. Original cloud components

Source: Cisco (2018).

Originally, enterprise resource planning (business) systems were packaged software which integrated information and supported organisational operations, basically manufacturing (Nguyen, Nguyen, \& Misra 2014).

To take advantage of the growing speed of internet connections and cost-savings, firms outsourced their databases and information and communication systems from in-house infrastructure and personal computers (Stair \& Reynolds, 2014). Cloud based data providers offered disaggregated information-intensive systems specific to each organisation (Manning et al., 2018). Kuettner (2012) pointed out that these integrated data systems offered flexibility, responsiveness, and agility through supply chains; of importance to global trade.

Cloud-based data management and storage systems are now being 'overlaid' by newer forms such as distributed ledgers, 'big data' processors, and the internet of things, that is, increasingly interconnected physical objects and infrastructure, such as driverless cars. Further quanta of data are used by artificial intelligence used in manufacturing robots, leading to the fourth industrial revolution (Manning et al., 2018).

Risk avoidance is another aspect of cloud use, such as banking and other personal data, data collected from monitoring sensors, tracking mobile data sources, authentication, and authorisation (Thota, Sundarasekar, Manogaran, Varatharajan, \& Priyan, 2018). The integrity of the cloud provider should be established, and also the ability to move to other providers in case of contract failure (Goyal, 2013). However, Spyra, Buchanan, Cruickshank, \& Ekonomou (2014) pointed out that encryption remains the highest form of data protection. 
Aspects of a data governance strategy, according to Al-Ruithe, Benkhelifa, and Hameed (2018), include an overall corporate governance; governance of information; then separate aspects of data, infrastructure and cloud governance.

As part of globalisation, technological change, supply chains, and competition have changed Saudi management's views on in-house systems, given that their data may well be shared by international suppliers and customers. Further, interactions with retail customers require significantly more data (Awad, 2014; Leeflang, Verhoef, Dahlström, \& Freundt, 2014). Thus adopting modern technologies such as cloud-based services both fulfils the organisation's existing needs, and by hiring services rather than owning them, opens up considerable future data opportunities for management (Abdullahi \& Hussain, 2016).

\subsection{Cloud ERP Systems}

Cloud ERP primarily is introduced in terms of the 'Replace' strategy, where the new CERP system is delivered as a service and replaces the existing traditional ERP system.

There were various descriptors for 'cloud' computing prior to 2009. Rochwerger et al. (2009, p. 1) described a 'modular, extensible cloud architecture with intrinsic support for business service management and the federation of clouds'; thus establishing cloud-based computing as a business system. The United States' Institute of Standards and Technology extended this to a convenient, on-demand access to 'a shared pool of configurable computing resources (e.g., networks, servers, storage, applications, and services)' (Mell \& Grance, 2011). Cloud computing required minimal management effort from its customers and had automated service provider interaction. There are five characteristics of cloud computing:

- On-demand self-service: server time and network storage are automated.

- Broad network access: available from any Internet-enabled device.

- Resource pooling: consumers assigned capacity on demand; allocation to specific sites negotiable.

- Rapid elasticity: arguably unlimited.

- Measured service: usage monitored, controlled, and reported (Mell \& Grace, 2011, adapted from pp. 2-3).

Cloud services were originally provided as software as a service (SaaS) (e.g. SalesForce); platform as a service (PaaS) (e.g. Google AppEngine); and infrastructure as a service (IaaS) (e.g. Amazon EC2) (Chang, Walters, \& Wills, 2013). Services were available as public cloud, freely available and externally managed; private cloud has features of the public cloud whilst an organisation retains control of their resources; and a hybrid cloud ameliorates the disadvantages of a private cloud by a corporation using both (Toosi, Calheiros, \& Buyya, 2014). Toosi et al. pointed to the benefits of cloud use for organisations: low cost, low technical expertise necessary, scalable, and the technology remain current with rented software, platforms and infrastructure. A consortium of researchers (Buyya et al., 2017) stated that the emergence of cloud computing as a utility offered universal subscription services to 


\section{Mll Macrothink}

International Journal of Management Innovation Systems

ISSN 1943-1384

firms. The researchers claim that start-up entrepreneurs could establish faster, that enterprises could scale up internationally, research and development was faster and cost-effective, and that firms could switch between business models as they grew.

In Kingdom of Saudi Arabia, the adoption of Cloud ERP is at a nascent stage and most organizations, public or private are still to face the challenges of cloud ERP implementation (AlBar \& Hoque, 2017). Many large-scale organizations are considering adopting cloud ERP systems, especially in the educational industry. Most of the cloud computing firms are targeting the educational institutes in Kingdom of Saudi Arabia to assist with their integration problems. Most of the IT companies like Google, Microsoft and IBM are providing technology solutions to higher educational institutes in the country (Tashkandi \& Al-Jabri, 2015).

In Kingdom of Saudi Arabia, the motivational factors of cloud adoption are technology readiness, organizational readiness, environmental factors such as competition and available usage of resources (Tashkandi \& Al-Jabri, 2015). The private sector of Kingdom of Saudi Arabia is also eager to adopt Cloud ERP systems in their organizations due to intense competition in the market. (Khater \& Rashed, 2017) uses the TOE model to check the factors that are more important in the adoption of the ERP system. The IT managers of the $35 \%$ of private firms that answered say they are early adopters of the technology, while $65 \%$ of the organizations answered that they are not adopting Cloud ERP. The main reasons reported by the managers were the security, trust and privacy issues, compliance with regulations, compatibility and physical location of the technology. A study (ALresheedi, Lu, Maolood, Fatanid, \& Ince, 2018) investigated the adoption of Cloud ERP in Kingdom of Saudi Arabia by using the TAM model. The results of the study support the TAM model in the Kingdom of Kingdom of Saudi Arabian environment. One group (Alharbi, Atkins, \& Stanier, 2017) conducted a qualitative study in the health sector of Kingdom of Saudi Arabia to find the benefits and challenges behind the adoption. In healthcare, the five factors that are most influential are technology, human, environment, organization, and business.

\subsection{Vision 2030}

The 2030 vision of the Kingdom of Saudi Arabian economy is to diversify the economy by reducing the dependence on oil and by developing health, communication, technology, tourism, infrastructure, and education. Most of the companies have their own vision of 2030, to improve the infrastructure of the business. The country is approaching digital transformation with the help of digital services providers such as Oracle. The government is approaching the digital transformation to empower the individual and organizations. The use of new technology will help to improve the production and trade of the country at the international level (Alharbi, Atkins, \& Stanier, 2017). Cloud ERP is an example of the new technology enabling this digital transformation.

The portfolio for the Ministry of Commerce and Investment (2018), established in 2003, focuses on trade, and the Minister travels extensively to promote Kingdom of Saudi Arabia as an investment centre. The Ministry has wide powers for setting policy, regulating and enforcing regulations and quality standards for all sectors of the private sector, including 


\section{Mll Macrothink}

International Journal of Management Innovation Systems ISSN 1943-1384

regulating the Chambers of Commerce. It is also responsible for foreign trade relations including World Trade Organisation communications, Gulf Cooperation Council trade standardisation negotiations, promoting industry innovation, and chairing relevant regulatory and advisory committees such as consumer affairs. The Ministry takes a lead position in the government's Saudisation program, Nitaqat, where organisations are presented with quotas for Saudi national employment. It is also involved in workplace qualifications for Saudis, improving public sector productivity, developing private-public sector relationships, physical environment protection and wider trade relationships (Ministry of Commerce and Investment, 2018).

The Ministry of Transport, responsible for posts, telephones, and telegraphs, was established in 1953 (Ministry of Communications and Information Technology, 2018). Communications were extremely difficult under desert conditions, dependent on radio rather than wires that could be abraded by sandstorms. In 1975 the Ministry of Posts, Telegraphs and Telephones was taken out of Transport; however, at the time there was just two telephone services per 100 population (World Bank, 2018a). Incidentally, fixed landlines peaked in 2013 at 16.5 per hundred population, then dropped sharply to 11.3 per 100 population in 2015 . Optical fibre cables were first installed from 1984; satellite telecommunications services were available from 1986; and in 1995 mobile telecommunications services were introduced. In 1998, administration of postal, telegraph and telephone establishments were taken from the control of the Ministry and placed in a government-owned Corporation, the Saudi Telecom company. In response to impending use of the Internet, the Saudi Communications and Information Technology Commission was established in 2001, and in 2003, the Ministry's name was changed back to Communications and Information Technology (2018).

The Ministry of Communications and Information Technology (2018) responsibilities include the regulation and promotion of communications technology in Kingdom of Saudi Arabia. Besides responsibility for international relationships and conforming to international protocols, the Ministry guides and monitors the e-government policy of 2003 the National Communication and Information Technology Plan, whereby all government services and transactions were to be provided online. In 2007, the Ministry regulated online security standards and established funds transfer protocols; and in 2008 the fixed landline service was opened to the private sector, as well, regulations for the Electronic Transactions Law were issued. Licences for mobile virtual networks were issued in 2014 (Ministry of Communications and Information Technology, 2018). The Communications and Information Technology Commission (2016) reports annually on communications technology in the Saudi business sector, stating that at the end of that year, 349 licences were issued to a range of sector providers, from fixed infrastructure (2) to short messaging services (94).

The other Ministries who influence data management and cloud service providers in the business sector are Culture and Information, Education, Finance, Labour and Social Development, and National Economy and Planning. For management and employee competencies, that is, Saudisation and Nitaqat, the Ministries of Education, Finance, and Labour and Social Affairs are responsible. The remaining elements of the governance structures are the 28 Chambers of Commerce and Industry, partly funded by the government 


\section{Macrothink}

International Journal of Management Innovation Systems

ISSN 1943-1384

to act as a conduit for advice and information, generally to smaller firms. There is a National Committee for Information Technology, but no further details are available (Council of Saudi Chambers, 2018).

\section{Methodology}

As social research, a qualitative study plan was selected that was based on a multiple case approach (Yin, 2013. As the organisations' resources, business sectors and needs differed, their experiences in meeting those needs and achieving integration with the organisations' suppliers and customers also differed. For this purpose, Bryman (2016) advised in selecting senior managers knowledgeable in the phenomenon (integrating cloud technology into the business model). Further, a range of small, medium and large firms was selected to maximise coverage of Saudi industry types. Up to four face-to-face interviews were held with managers and technical staff from each firm, plus emails for those off-site or staff who preferred email questions. The table shows the profile for each company, including size (number of employees), and the dates they began to move to cloud services.

Table 1. Summary of participant firms

$\begin{array}{llllll}\text { A. } & \text { B. } & \text { C. } & \text { D. } & \text { E. } & \text { F. }\end{array}$

\begin{tabular}{lcccccc}
$\begin{array}{l}\text { Firm } \\
\text { characteristics }\end{array}$ & $\begin{array}{c}\text { Website and } \\
\text { graphic } \\
\text { designers }\end{array}$ & $\begin{array}{c}\text { Engineering } \\
\text { and } \\
\text { construction }\end{array}$ & $\begin{array}{c}\text { Data } \\
\text { infrastructure }\end{array}$ & Airline & $\begin{array}{c}\text { Software } \\
\text { trading }\end{array}$ & $\begin{array}{c}\text { Hydrocarbons } \\
\text { industry }\end{array}$ \\
\hline $\begin{array}{l}\text { Adopted cloud } \\
\text { technology }\end{array}$ & 2012 & 2014 & 2014 & 2016 & 2014 & 2010 \\
\begin{tabular}{l} 
Employees \\
\hline
\end{tabular} & $150+$ & $200+$ & $400+$ & $45000+$ & $100+$ & $60000+$ \\
\hline
\end{tabular}

As shown in the table, the firms migrated their business systems to cloud service providers over time. The smaller firms arguably had less legacy software and could manage the transition easily, whilst the larger firms perhaps worked through standing financial and contractual obligations.

Data were collected through semi-structured interviews designed to direct the flow of questions, whilst allowing flexibility for participants to explain the characteristics of their particular cloud integration process. Lee and Malerba (2017) argued that technological change opens windows of opportunities that firms and countries can exploit. Analysis of the data, as a comparative study, first involved a case by case approach, then the concepts and themes that emerged were compared to understand the post-cloud strategies and experiences of the firms. The conclusions for the study were derived from this process (Bryman, 2016; Yin, 2013).

\section{Results}

Each firm was described as a case matrix: its business model, capacity, transition and 
structure of cloud technologies, and outcomes.

\section{Company A}

Company A was a full-service provider of business systems, mobile voice and data systems, a local subsidiary with headquarters in the United Kingdom. In 2011 it was finding difficulty in sourcing equipment and parts for its Saudi clients' in-house systems infrastructure. Company A representative, participant 1 of this study, explained that the firm was also a retail leader in integrated data services, and to retain this advantage it decided to outsource its internal data management to cloud providers and concentrate on building cloud software solutions for its clients. The firm's own cloud migration experience was a useful experiment in offering such services to clients

The emerging value in global cloud data management and storage led Saudi organisations to abandon older technologies and migrate to cloud services as they became increasingly reliable, secure, scalable, and cost-effective. Leasing services lowered the firms' data management risks and allowed them access to industry standard technologies. Despite local challenges of government controls, protocols, and licensing of cloud components (eventually regulated in 2018), the paradigm shift to cloud data management proved highly profitable for company A.

Company A participants said issues in cloud migration in 2012 with the country's indifferent internet service required substantial data backup and security. This was managed through the service level agreement so that the provider to company A absorbed the risk of outages through distribution to several suppliers, a service that company A could not provide on its own. Nevertheless, company A retained its onsite backup servers for its clients until that, too, could be a cloud provider service. Having divested itself of these functions, company A participants reported that despite continuous technological change, their cloud provider was highly successful in managing the company's needs. This freed up company A to focus on its own customers' needs with a new business model as data management consultant and adviser.

\section{Company B}

Established in Dammam in 1990, company B was an engineering corporation with expanding operations across the Arabian Peninsula and southern Asia. Because of its many locations and varied supply chains and customers, the firm's information systems needed networking and standardising for reporting and decision making both locally (nationally) and at headquarters. There were also mismatches between company B's various data systems and those of its suppliers and larger customers.

Participant 5 explained that in 2013, company B was using inhouse systems such as email reports that were proving increasingly inadequate. Company B had major bulk suppliers in China, the United States and India, and smaller high-end suppliers in Europe and the United States. When a valued European supplier notified company B that they would have to automate orders and online payments, the board decided to upgrade its data management. A project team was appointed to manage the process and participant 6 said that they found significant variability between the systems and in their capabilities. A specification was 
developed and distributed to cloud systems consultants, who were then shortlisted according to competency assurances, offers, and service level agreements. Three were selected and their representatives travelled to each branch with participant 6 to learn about the local environments. The results from each against criteria in the offers were collated by the project team, a decision made, and it was approved by company B's board in 2013.

The cloud capability envisaged by the selected cloud consultants, SAP, was tiered to account for the various encryptions for the data held and managed by the company. In the plan, company B's business systems included head office data interfaces in real time to bring operational reports into the respective head office divisions for preparation for an executive dashboard (summary page). These reports included suppliers' orders and their status, customer orders and their status, goods in transit and storage, and finance. As well, company B's administration, and marketing and sales were included. The human resources function was outsourced, so that became an executive responsibility. Supply chain software such as the European example was accommodated on another tier networked to the business systems. Thus each data point, tier, and capability could be expanded to accommodate specific flows, such as seasonal, and automatically upgraded as required by SAP. Whilst mobile phones were supplied to all employees and in-house contractors, these were not internet connected, nor were social media used initially for sales.

The outcomes for company B were a satisfactory transition from older uncompetitive computer systems to take up internet-enabled functions such as online ordering, confirmation, and payment through supply chain systems; collecting customer data for targeted sales; managing and comparing supplier offers across the firm's branches and thus identifying substandard services in various locations. Participant 5, the executive, said that the firm had really expected more disruption than occurred during the transfer, and the executive credited the project manager for the planning and execution of the transfer. The executive further pointed out that whilst the business model was initially retained, it was subject to continual review as the corporation advanced.

\section{Company C}

This case was a regional infrastructure information and communications provider established in 2005 in Riyadh. Participant 9 said that they were part of a larger multi-industry conglomerate, although the firm was a distinct entity. Company $\mathrm{C}$ provided business to business solutions for its customers; it also leased wired and wireless data services from its in-house systems platforms. This case differed from the others as the firm was part of an oligopoly of infrastructure providers.

Participant 9 said that as an infrastructure data provider, the firm was well placed to bundle its products into cloud-based services, using its data networks, data centres, cable facilities, and satellite resources. As cloud services comprise infrastructure, platform and software programming, company $\mathrm{C}$ extended its business services through entities in its parent corporation and developed a set of integrated services (products) that customers could access under a services agreement. 


\section{Mll Macrothink}

International Journal of Management Innovation Systems

ISSN 1943-1384

2019, Vol. 4, No. 1

Despite its predominant infrastructure position, participant 11 said that company $\mathrm{C}$ was not in a position to provide true cloud services, as it was using partnerships in the conglomerate instead of offering a seamless service. It had little incentive to change its business plan so that it set up a subsidiary to offer its 'cloud services' rather than developing an integrated package. As participant 11 commented, it may be that infrastructure firms are not qualified in software services, that Amazon, Google and Microsoft were global examples of software firms developing infrastructure, rather than the reverse as company $\mathrm{C}$ attempted. Arguably, company $\mathrm{C}$ may not have initiated the new cloud company, although its logo was used.

\section{Company D}

With its head office in Jeddah, the international airline company was dominant in its industry. As such, company D used global system networks for flight, ground operations, suppliers, customers, and administration. Participant 13 explained that company D moved its business systems to SAP regional data centres (cloud), in 2016. This was part of the board's commitment to service improvements under the Saudi government's Vision 2030. The legacy system, Business Suite, had three tiers: a presentation system that was generated as a self-contained component; an online server; and security, which became end to end data encryption.

Participant 13 said that company D was familiar with SAP, and the firm's cloud S/4HANA offered enhancements to its data management systems that included integration between head office and its subsidiaries; improved automation through machine learning (a performance feedback loop); and data mining of key measures to present executive with current data and predictive analytics. However, S/4HANA was standalone, not connected to company D's supply chains, aircraft operations, or regulatory national systems in the countries of its subsidiaries.

Customer service was managed differently, using Windows servers on Azure cloud, Microsoft SQL cloud, Apache cloud and Linux open source software (participant 16). Participant 15 said that the company was launching a customer relations management system to address problems that arose during the annual hajj when over a month there were up to three million pilgrims in transit. Another aspect was airport operations. Participant 15 explained that misplaced baggage was a global issue, as airlines, airports and ground handlers could spend significant time and resources tracking misplaced luggage. Company D was at the time investigating one such provider of tracking services, SITA's BagJourney.

Company D was cautious in proceeding in 2015 with its highly complex systems development: varying levels of data management at international airports; industry-level aircraft systems and passenger systems; its own business systems, such as customer management, and very high compliance obligations. Whilst experienced cloud providers installed the new systems, company D's local staff were tasked with operations and fulfilling the potential for cloud technologies. This was the aim of the government in Vision 2030, where young Saudis unused to an intense private workplace environment had the responsibility for managing these systems. 


\section{Mll Macrothink}

International Journal of Management Innovation Systems

ISSN 1943-1384

Company D's executive participant acknowledged the challenges of disruptive change which would be ongoing as systems evolved. In all, the company was a part of an international industry and as such, in a supply chain for its assets, resources, passengers (travel agencies), and operations.

\section{Company E}

In 2014, company E's business model was advice and supply of computers, electronics and software packages for students, homes, and businesses. Mobile communications were increasingly internet-connected and very popular, so that management planned to divest its multi-product range, and concentrate on mobile devices for which it could offer setup, application packages, and ongoing support to small firms and schools. Company $\mathrm{E}$ thus planned to reconfigure its business model from a multi-customer heritage product range to a new model specialising in online devices and developing tailored platforms (operating systems for servers) and apps for specific purposes (software as a service).

In changing its business plans, management brought in business system analysts who identified the various complementary sectors of the business and reconfigured these as modules that could be sold off. The firm retained the mobile device businesses for its cloud services. Company E's model was flexible: it could either use its partners to build inhouse software on these platforms as a service for clients, or clients could use their own developer resources. To engage the youth market, the company started a service for small startup enterprises. This division was growing rapidly. One such client was participant 20 from a three-person business who undertook software development for company E on contract in an ad hoc capacity. The business also built gaming software and incremental apps and sold these on social media.

Another partnership of company E's flexible model was represented by participant 19, an educational consultant. This educational firm was in a service agreement with company $\mathrm{E}$, rather than the ad hoc contractual arrangement of the youth market. This firm developed curricular software for public schools which was highly specialised and formulaic. Participant 19 said that the courses and pedagogical support materials could be customised for student ages, locations, and some disabilities. Company E therefore developed a hybrid business plan that accounted both for its legacy businesses whilst taking advantage of ongoing technological changes and opportunities.

\section{Company $\mathbf{F}$}

A multinational hydrocarbons corporation, company F was headquartered in Dhahran. Unlike the other large organisation, D, which was bound by industry standard information systems as part of its global alliances, $\mathrm{F}$ was autonomous due to its status as arguably the world's richest enterprise. Company F's focus moved to information technology in the 1990s (participant 21) with a separate marketing and distribution centre in Jeddah. By 2000, company F opened its first research and development centre, concentrating on building information technology infrastructure, data analysis, and systems modelling. The company continued to develop its business systems on SAP infrastructure. Participant 21 explained that the company expanded 
rapidly in the 2010s and company F's status ensured that it was a first adopter of cloud technologies. This observation was similar to that of company D, so that conglomerates' data systems operated on a very different level to the smaller organisations in this study. For example, SAP Ariba in 2017 was developing its SAP Cloud Hub on the Arabian Peninsula in partnership with company F. As 'private clouds', company F's data platforms served its divisions including oil recovery enhancement; developing geochemical techniques; integrated reservoir studies that incorporated both static and dynamic data flows; and especially to reduce energy use in refining products.

With company F's oil strategies, it would appear that it was positioning in the data environment of robots, integrated sensor networks, large scale data analysis and future diversification or break-up. Currently it is amongst the largest oil producers; this may be a precursor to moving from its oil industry foundations to become one of the largest data management corporations.

\section{Analysis}

Analysis showed that the two technology industry participants, companies A and E, were in the process of implementing new business concepts which were following the leadership of the large firms D and F, that is, a strategy of continual development. As data services became more complex through greater automation of home and business services, evolving new products was of more importance for the smaller firms than control and operation of basic data systems, so these were outsourced.

Another finding was that the international suppliers of data services the case companies used originally were, similar to $\mathrm{A}$ and $\mathrm{E}$ companies, integrating components of their data management to offer seamless products, that is, developing a customer focus towards the case companies and outsourcing their own infrastructure. Even company $\mathrm{C}$ was partnering a new company whereby potential customers were offered a menu of services (products) to meet their needs. A large German firm, SAP, was (belatedly) updating its airline industry protocols for company D's migration to cloud; undoubtedly many other airlines were simultaneously upgraded. Company B's migration was possibly the most complex, as it was a taker rather than a maker of the chain data management and thus was not in a good position to force its own customers away from their invoicing and payment routines.

Outcomes were that companies A and E were satisfied with maintaining or achieving industry position after adopting cloud provision. Company B reduced its risks and, with company $\mathrm{E}$, simplified their operations and reduced overall costs. The larger companies were least affected by the use of cloud business systems, as company C (infrastructure) and company D (airline) were recipients of corporate and industry provider decisions. Company $\mathrm{F}$, the oil and gas conglomerate, was also in the position (with company $\mathrm{C}$ ) of using its resources to advance into the emerging fields offered by technology changes.

\section{Conclusions}

The overarching conclusion was that the cases depicted from the Saudi private sector were accepting new technologies, supported by the 2018 Cloud Computing Regulatory Framework. 
Again, early concerns of security of data were in time addressed by encryption of sensitive data and use of dedicated servers or private cloud. With these assurances, Saudi providers such as company E were finding niche clients such as Ministry of Education's open opportunities for service agreements for curricula platforms and future course content.

A conclusion from the findings is that firms were certainly taking advantage of the greater freedom in conducting business through cloud provision. Cloud services, as platform and software, were widely available through local and international providers, and there were dedicated services for industries (hydrocarbons, airlines) or smaller configurations such as supply chains.

Cloud ERP aligns with Vision 2030 as it has economic benefits such as less capital hardware requirement, faster expansion, quicker return on investment, cost saving, and improving opportunity cost. The economy of Kingdom of Saudi Arabia can be boost by using the integrated cloud ERP system. When small and medium-sized organization implements Cloud ERP, then there will be more production of goods and services that lead to more trade of goods and services with the world. This will boost the Kingdom of Saudi Arabian economy (Rafique, Tareen, Saeed, Wu, \& Qureshi, 2011).

As can be seen, Cloud ERP aligns with several of the objectives of Vison 2030, Cloud ERP is well-placed to provide better data services to entrepreneurs and small businesses.

\section{References}

Abdullahi, A., \& Hussain, F. (2016). An exploratory study on the adoption of private cloud in the UAE banking and government sectors. International Journal of Business and Globalisation, 16(2), 129-148. https://doi.org/10.1504/IJBG.2016.074487

Akhter, F. (2017). Unlocking digital entrepreneurship through technical business process. Entrepreneurship and Sustainability Issues, 5(1), 36-42. Retrieved from https://hal.archives-ouvertes.fr/hal-01724064

AlBar, A., \& Hoque, M. (2015, 26-29 April). Determinants of cloud ERP adoption in Saudi Arabia: An empirical study. In 2015 International Conference on Cloud Computing (ICCC), Riyadh, KSA. New York, NY: IEEE. https://doi.org/10.1080/02681102.2017.1390437

Alharbi, F., Atkins, A., \& Stanier, C. (2017). Cloud Computing Adoption in Healthcare Organisations: A Qualitative Study in Saudi Arabia Transactions on Large-Scale Data and Knowledge-Centered Systems XXXV (pp. 96-131). Springer.

Alharbi, F., Atkins, A., \& Stanier, C. (2017, 12-15 September). Holistic strategic assessment and evaluation of cloud computing adoption: Insights from Saudi healthcare organisations. In Internet Technologies and Applications (ITA), Wrexham, Eng. (pp. 75-80).

Al-Jabri, I. \& Alabdulhadi, M. (2016). Factors affecting cloud computing adoption: Perspectives of IT professionals. International Journal of Business Information Systems, 23(4), 389-405. Retrieved from https://ssrn.com/abstract=2939925

Al-Maliki, S. (2013). Information and communication technology (ICT) investment in the 


\section{MInstitute Macrothink $^{\text {Int }}$}

International Journal of Management Innovation Systems

ISSN 1943-1384

Kingdom of Saudi Arabia: Assessing strengths and weaknesses. Journal of Organizational Knowledge Management, 1-15. https://doi.org/10.5171/2013.450838

Alresheedi, S., Lu, S., Maolood, I. Y., Fatanid, A. A., \& Ince, M. (2018). An investigation of influential factors in adopting cloud computing in Saudi Arabia: an application of the technology acceptance model. International Journal of Engineering \& Technology, 7(4), 3623-3629.

Al-Ruithe, M., Benkhelifa, E., \& Hameed, K. (2018). Data governance taxonomy: Cloud versus non-cloud. Sustainability, 10(1), 95, 1-26. https://doi.org/10.3390/su10010095

Awad, H. (2014). One ERP system for twenty five universities: An empirical investigation for development ERP private cloud Kingdom of Saudi Arabia universities case. International Journal of Advanced Research in Computer and Communication Engineering, 3(4), 6365-6368.

Bloomberg Business Week Middle East. (2018, 18 April). Rise of the cloud. Retrieved 6 June 2018 from http://businessweekme.com/rise-of-the-cloud/

Bryman, A. (2016). Social research methods (5th ed.). Oxford Eng: Oxford University Press.

Buyya, R., Srirama, S., Casale, G., Calheiros, R., Simmhan, Y., Varghese, B., ... \& Toosi, A. N. (2017). A manifesto for future generation cloud computing: Research directions for the next decade. Cornell University Library arXiv preprint arXiv:1711.09123.

Chunlin, L., \& LaYuan, L. (2017). Optimal scheduling across public and private clouds in complex hybrid cloud environment. Information Systems Frontiers, 19(1), 1-12. https://doi.org/10.1007/s10796-015-9581-2

Cisco Global Cloud Index. (2018). Cisco Global Cloud Index: Forecast and methodology, 2016-2021: White paper. Retrieved 6 June 2018 from https://www.cisco.com/c/en/us/solutions/collateral/service-provider/global-cloud-index-gci/w hite-paper-c11-738085.html

Communications and Information Technology Commission. (2017). ICT report: E-commerce in Saudi Arabia. Retrieved 11 June 2018 from http://www.citc.gov.sa/en/reportsandstudies/Reports/Documents/CITC_ECOMMERCE_2017 _ENGLISH.PDF

Council of Saudi Chambers. (2018). National Committee for Information Technology. $\begin{array}{llll}\text { Retrieved } & 14 & \text { June } & 2018 \\ \end{array}$ http://www.csc.org.sa/English/NationalCommittees/NationalCommitteesList/com202/Pages/d efault.aspx

Geronimo, A. (2018, 4 June). Cloud drives Saudi ICT market to top $\$ 33$ billion. $\begin{array}{llllll}\text { Tahawultech.com. } & \text { Retrieved } & 6 & \text { June } & 2018 & \text { from }\end{array}$ http://www.itp.net/617236-stc-inaugurates-new-main-data-centre

Goyal, S. (2013). Perils of cloud based enterprise resource planning. Advances in Asian 
Social Science, 4(3), 880-881. https://doi.org/10.5815/ijcnis.2014.03.03

Grabski, S., Leech, S., \& Schmidt, P. (2011). A review of ERP research: A future agenda for accounting information systems. Journal of Information Systems, 25(1), 37-78. https://doi.org/10.2308/jis.2011.25.1.37

Khater, A., \& Rashed, N. (2017). A model of a private sector organisation's intention to adopt cloud computing in the Kingdom of Saudi Arabia. University of Southampton.

Kuettner, T. (2012, 14-16 March). Functions or flexibility. The role of agility in business software. Paper presented at the $8^{\text {th }}$ International Association for Development of Information Society's Information Systems Conference, Madeira, Portugal.

Labovitz, C., Iekel-Johnson, S., McPherson, D., Oberheide, J., \& Jahanian, F. (2011). Internet inter-domain traffic. ACM SIGCOMM Computer Communication Review, 41(4), 75-86. https://doi.org/10.1145/1851275.1851194

Lee, K., \& Malerba, F. (2017). Catch-up cycles and changes in industrial leadership: Windows of opportunity and responses of firms and countries in the evolution of sectoral systems. Research Policy, 46(2), 338-351. https://doi.org/10.1016/j.respol.2016.09.006

Leeflang, P., Verhoef, P., Dahlström, P., \& Freundt, T. (2014). Challenges and solutions for marketing in a digital era. European Management Journal, 32(1), 1-12. https://doi.org/10.1016/j.emj.2013.12.001

Manning, S., Larsen, M., \& Kannothra, C. (2018). Global sourcing of business processes: History, effects, and future trends. In G. Clark, M. Feldman, M. Gertler, \& D. Wójcik (Eds.), New Oxford Handbook of Economic Geography. Oxford, Eng: Oxford University Press.

Mell, P., \& Grance, T. (2011). The NIST definition of cloud computing. United States National Institute of Standards and Technology. Retrieved 30 October 2018 from http://faculty.winthrop.edu/domanm/csci411/Handouts/NIST.pdf

Menabytes. (2018, 6 March). Saudi Aramco eyeing expansion into cloud computing and data $\begin{array}{llllll}\text { analytics. } & \text { Retrieved } & 6 & \text { June } & 2018 \text { from }\end{array}$ https://www.menabytes.com/saudi-aramco-cloud-computing/

Ministry of Commerce and Investment. (2018). About the Ministry. Retrieved 14 June 2018 from https://mci.gov.sa/en/Pages/default.aspx

Ministry of Communications and Information Technology. (2018). Brief history. Retrieved 14 June 2018 from https://www.mcit.gov.sa/en/brief-history

Nguyen, T. D., Nguyen, T. T., \& Misra, S. (2014, 19-21 November). Cloud-based ERP solution for modern education in Vietnam. In T.K. Dang, R. Wagner, E. Neuhold, M. Takizawa, J. Küng, N. Thoai (Eds.), Proceedings of Future Data and Security Engineering First International Conference, FDSE 2014, Ho Chi Minh City, Vietnam (pp. 234-247). Cham, Switzerland: Springer. DOI: https://doi.org/10.1007/978-3-319-12778-1_18

Paul, K. (2017). Exclusive: Apple and Amazon in talks to set up in Saudi Arabia - sources. 
Reuters. $\quad$ Retrieved

7

June

2018

from

https://www.reuters.com/article/us-saudi-tech-exclusive/exclusive-apple-and-amazon-in-talks -to-set-up-in-saudi-arabia-sources-iduskbn1em0pz

Rafique, K., Tareen, A. W., Saeed, M., Wu, J., \& Qureshi, S. S. (2011). Cloud computing economics opportunities and challenges. Paper presented at the 2011 4th IEEE International Conference on Broadband Network and Multimedia Technology.

Rochwerger, B., Breitgand, D., Levy, E., ... \& Galan, F. (2009). The Reservoir model and architecture for open federated cloud computing. IBM Journal of Research and Development, 53(4), 1-11.

Sheikh, Z., Islam, T., Rana, S., Hameed, Z., \& Saeed, U. (2017, August). Acceptance of social commerce framework in Saudi Arabia, Telematics and Informatics. https://doi.org/10.1016/j.tele.2017.08.003

Spyra, G., Buchanan, W., Cruickshank, P., \& Ekonomou, E. (2014). Cloud-based identity and identity meta-data: Secure and control own data in globalization era. International Journal of Reliable and Quality E-Healthcare, 3(1), 49-66. https://doi.org/10.4018/ijrqeh.2014010105

Stair, R., \& Reynolds, G. (2014). Principles of information systems (11th ed.). Mason OH: Cengage Learning.

Sutton, M. (2018, 3 June). STC inaugurates new main data centre. ITP Centre.com. Accessed 6 June 2018 from http://www.itp.net/617236-stc-inaugurates-new-main-data-centre

Tashkandi, A. \& Al-Jabri, I. (2015). Cloud computing adoption by higher education institutions in Saudi Arabia: An exploratory study. Cluster Computing, 18(4), 1527-1537.

Thota, C., Sundarasekar, R., Manogaran, G., Varatharajan, R., \& Priyan, M. (2018). Centralized fog computing security platform for IoT and cloud in healthcare system. In A. Krisna Prasad (Ed.), Exploring the convergence of big data and the internet of things. Hershey, PA: IGI Global

Toosi, A., Calheiros, R., \& Buyya, R. (2014). Interconnected cloud computing environments: Challenges, taxonomy, and survey. ACM Computing Surveys, 47(1), 7.

Umar, R., Sheikh, A., Deriche, M., Shoaib, M., \& Hadi, M. (2017, 19-22 November). Multi-operator spectrum sharing in next generation wireless communications networks: A short review and roadmap to future. In 2017 International Symposium on Wireless Systems and Networks (ISWSN) Lahore, Pakistan (pp. 1-5). New York, NY: IEEE. DOI: https://doi.org/10.1109/ISWSN.2017.8250015

Walden, I. (2018). Saudi Arabia regulates cloud computing services. Retrieved 5 June 2018 from

https://www.bakermckenzie.com/en/insight/publications/2018/03/saudi-arabia-regulates-clou d-computing

World Bank. (2018a). Saudi Arabia. Fixed telephone subscriptions per 100 population. 


\section{Macrothink}

Retrieved

14

International Journal of Management Innovation Systems

ISSN 1943-1384 2019, Vol. 4, No. 1

https://data.worldbank.org/indicator/IT.MLT.MAIN.P2?locations=SA\&view=chart

Yin, R. (2013). Case study research: Design and methods (5th ed.). Thousand Oaks, CA: Sage.

\section{Copyright Disclaimer}

Copyright for this article is retained by the author(s), with first publication rights granted to the journal.

This is an open-access article distributed under the terms and conditions of the Creative Commons Attribution license (http://creativecommons.org/licenses/by/3.0/). 